\title{
LA FILOSOFÍA Y LA PSICOLOGÍA EN LA HERMENÉUTICA LITERARIA DE LA ILUSTRACIÓN ${ }^{1}$
}

\author{
PHILOSOPHY AND PSYCHOLOGY IN THE LITERARY \\ HERMENEUTICS OF ENLIGHTENMENT
}

\author{
María José RODRÍGUEZ SÁNCHEZ DE LEÓN \\ IEMYRhd-Universidad de Salamanca \\ szleon@usal.es
}

Resumen: En este trabajo se estudia la vinculación entre la creación de una Hermenéutica literaria en el Siglo de las Luces y el desarrollo de la Filosofía y la Psicología en la época. Se plantea de qué modo y en qué medida, la constitución de una Hermenéutica literaria estuvo determinada por la incidencia de los planteamientos filosóficos de la época, desde la vertiente más racionalista a la más sensualista. En la misma medida, se analiza la interpretación y la comprensión literaria teniendo en cuenta los factores psicológicos que daban sentido y función a la lectura de las obras literarias.

Palabras clave: Hermenéutica literaria, Filosofía, Psicología, Ilustración

Abstract: In this paper we study the relation between the emergence of Literary Hermeneutics in the Enlightenment and the development of Philosophy and Psychology in the Eighteenth Century. It raises how and to what extent the constitution of the Literary Hermeneutics was determined by the presence of the philosophical theories of that time, from the racionalist to the sensualist. In the same way, the interpretation and the literary comprenhension are analyzed based on the psychological factors that gave meaning and function to the reading of literary plays.

Palabras clave: Literary Hermeneutics, Philosophy, Psychology, Enlightenment.

\footnotetext{
${ }^{1}$ Este trabajo se inscribe en el marco del proyecto de investigación Teoría de la lectura y hermenéutica literaria en la Ilustración: edición de fuentes documentales y literarias (1750-1808) (FFI2016-80168-P) del Ministerio de Economía de Economía y Competitividad cofinanciado por el Fondo Europeo de Desarrollo Regional (FEDER).
} 


\section{1}

\section{La hermenéutica literaria en la Ilustración}

Cuando se habla de Hermenéutica se piensa en el "arte de la interpretación" (ars interpretationis) y en el ideal de la comprensión de las obras. En principio, la función hermenéutica consiste en "llevar a la comprensión" o "mediar en la comprensión"2. El Humanismo del Renacimiento implicó un desarrollo de la actividad hermenéutica, sobre todo de la filológica de clara matriz histórica. Tal antecedente, si bien adelantó problemas posteriores, se basaba en supuestos precientíficos sin los cuales, conviene añadir, no podrían comprenderse las investigaciones subsiguientes en relación con la búsqueda de un lugar propio para las "ciencias del espíritu" en oposición al ocupado por las "ciencias de la naturaleza" (Ferraris, 2000, pp. 48-57). En ese recorrido histórico también el siglo XVIII resultó fundamental.

Junto a una revalorización de la actividad filológica, historiográfica o crítica, el Setecientos, particularmente en su segunda mitad, aportó el desenvolvimiento y formulación de una hermenéutica universal y, unida a ella, se fue configurando, de forma más o menos consciente, una hermenéutica literaria de base científica. Autores como los alemanes Chladenius, Meier o Ast se plantearon en sus escritos la existencia o, mejor, la necesidad de establecer los criterios y funciones por los que debía regirse en la Modernidad una ciencia general de la interpretación (Szondi, 2006, pp. 41-192; Murcia, 2019, pp. 151-174 y Recio, 2019, pp. 175-184). De igual manera, quienes ejercieron la tarea de leer, analizar y juzgar la literatura consideraron que era necesario acometer estas y otras labores filológicas y hermenéuticas a partir de la creación de unos fundamentos epistemológicos, históricos o poéticos que permitieran superar las incertidumbres a las que se veía abocado el trabajo de los eruditos, de los críticos y de los filólogos ${ }^{3}$.

Esa hermenéutica universal, válida para la interpretación de cualquier clase de signo como proponía Meier (Murcia, 2019, pp. 151-173), habría de surgir de un referente intelectual, es decir, de una auténtica conciencia filosófica en la que pudieran encontrarse principios epistemológicos generales de acuerdo con los cuales se comprendieran los lenguajes simbólicos y, en nuestro caso, las obras

\footnotetext{
${ }^{2}$ Resulta necesario diferenciar entre interpretar y comprender. En sus orígenes míticos, la hermenéutica se asocia a la actividad práctica de comunicar o de mediar (Ferraris, 2000, pp. 9-11). Sin embargo, en la Edad Moderna el hecho de interpretar precisa de una metodología capaz de hacer comprensibles los textos. Encontrar su significado no es tarea sencilla sino que exige proveer de ciertas reglas de comprensión, además de que exige un grado de conciencia de la actividad en sí de interpretar. Como señala Heidegger, previo al hecho de interpretar, se encuentra el ser consciente de lo que implica (Couzens, 1982, pp. 2-3). El intérprete debe, pues, explicar las condiciones en las que se realiza el entendimiento o comprensión. El ideal se cifra en la consecución de la objetividad y esta en su discurrir es de origen cartesiano. A ello habría que añadir la historicidad como categoría ineludible por la propia condición histórica del ser humano y de su producción textual. Recuérdese que todo ello es relativizado por Gadamer para quien la comprensión es un fenómeno lingüístico (1997 [1970], pp. 99-114). Los antecedentes de esta visión de la hermenéutica podemos encontrarlos en la concepción dieciochesca de la interpretación como una actividad lingüístico-retórica que se recogen en mi trabajo (2019a). ${ }^{3}$ En estas afirmaciones queda imbricada la acción de interpretar y la de criticar. Si bien son actividades diferenciadas, la segunda exige la primera e incluso en la Modernidad la actividad hermenéutica sería difícil de disociar en la práctica de la crítica. Un caso paradigmático será el de Juan Andrés (Rodríguez Sánchez de León, 2019a).
} 
literarias. Mas, como señalara Chladenius y explican Szondi y Ferraris, la universalidad de la comprensión tropieza con la contradicción que supone, por una parte, el deseo de hallar principios universales que cumplan con el ideal de alcanzar la comprensión objetiva y, por otra, las limitaciones derivadas de la inevitable autoimplicación del sujeto en la interpretación. Supone esto aceptar o alcanzar cierto grado de conciencia lógica sobre la existencia de aspectos emotivos-subjetivos e históricos que pueden determinar el hecho en sí de comprender ${ }^{4}$. Así pues, apelar "a la razón y a las reglas que gobiernan el alma", como las denomina Chladenius ${ }^{5}$, supone, también según este autor, interpretar teniendo en cuenta lo que las palabras o los escritos son capaces no ya de designar sino también de suscitarnos (Mueller-Vollmer, 2000, p. 56, \&154 y 155). De forma general, y para ilustrar lo que pretendemos decir, citaremos a Maurizio Ferraris que en su Historia de la Hermenéutica señala lo siguiente:

La comprensión se ejercita sobre los objetos: la palabra denota una cosa y es a esta última a la que debe llegar el intérprete. La universalidad de la hermenéutica no nace de la reconstrucción de las intenciones del autor, sino de la posibilidad de todo intérprete de llegar hasta las cosas denotadas por las palabras contenidas en el texto. Pero la idea de la hermenéutica universal está acechada por otro aspecto de la razón ilustrada, a saber, por la libertad del intérprete respecto a la tradición; ciertamente la comprensión es un hecho que versa sobre objetos que están detrás de las palabras, pero es, de todos modos, un acto subjetivo que no puede ser prejuzgado desde algún presupuesto. El intérprete, vinculado por los objetos, es, sin embargo, libre frente a la tradición. Nace de aquí una contradicción entre ideales de libertad (subjetividad) y de universalidad (y objetividad) (2000, pp. 81-82). ${ }^{6}$

Mas este oscilar entre lo filosófico-racional, lo histórico y el componente psicológico-emotivoparticular que conlleva el hecho de leer, plantea una serie de problemas de difícil solución que se reflejarán en la construcción de una hermenéutica literaria dieciochesca.

\footnotetext{
${ }^{4}$ La idea de "comprensión completa" de Chladenius para los escritos racionales, esto es, aquellos a los que cabe aplicar el arte de la interpretación filosófica frente las Sagradas Escrituras (hermenéutica profana frente a hermenéutica sagrada) se realiza cuando "uno cree que alcanza todo lo que las palabras despiertan en nosotros" (1742, §155; Muller-Vollmer, 2000, p. 56). El problema, también señalado por el propio Chladenius, se encuentra en que el conocimiento de la lengua no es suficiente para la interpretación del sentido de un pasaje o de un texto (puede leerse en Szondi, 2006, p. 65).

5 "A meaningful oration or written work is presented or written in order to cause a stirring in our souls. These stirrings serve joy, laughter, seriousness, shame, sadness and other emotions. An obstacle may be present which does not allow these emotions to be awakened at certain times and in certain people. But, if in listenning to or reading a meaningful oration or writing one senses the intended emotion or at least sees that such an emotion could result if there were no obstacles, then one has fully understood that oration or writing" [Una oración o una obra escrita se presenta o se escribe con el fin de causar una sacudida en nuestras almas. Estas sacudidas provocan alegría, risa, gravedad, vergüenza, tristeza y otras emociones. Un impedimento puede darse que no permita que estas emociones se despierten en ciertos momentos o en ciertas personas. Pero, si al escuchar o leer una oración profunda o en un escrito uno percibe la emoción prevista o, al menos, ve que tal emoción podría alcanzarse si no hubiera obstáculos, entonces uno ha comprendido completamente la oración o la escritura] (Chladenius, 1742, §154; Muller-Vollmer, 2000, p. 56. La traducción es mía como en adelante salvo indicación en sentido contrario).

${ }^{6}$ En Chladenius la interpretación debe basarse en la consecución de ciertas certezas pero reconoce que esa seguridad interpretativa no nace, aunque probablemente debiera, de lo que los textos dicen o expresan sino también del hallazgo del significado de lo que el autor realmente significó o quiso significar. El ideal se sitúa entonces en la existencia de un texto que responda exactamente a lo que el autor quería decir mediante sus palabras (1742, §155 y 156; Mueller-Volmmer, 2000, p. 57). En realidad, se está planteando la existencia de una distancia lingüística del autor respecto del texto y de este respecto del lector. Pero es misión de este, según Chladenius, representarse lo que el autor tenía en mente cuando escribió. A este respecto, las asociaciones que pueda realizar el lector se realizan a partir de una lógica normativa que se adueña de lo psicológico para evitar que se impongan las “divagaciones de la imaginación” (Szondi, 2006, pp. 79-81).
} 
Dos precisiones previas han de ser realizadas. La primera concierne a la existencia misma de la "hermenéutica literaria". Si bien no podemos afirmar que esta se configurara en el siglo XVIII con la misma seguridad que se admite para el siglo XIX, sobre todo a partir de la publicación en 1838 del tratado de Friedrich D. E. Scheleiermacher Hermeneutics and Criticism, es innegable que el siglo XVIII la impulsó de forma determinante ${ }^{7}$. No obstante, en lo que a las obras literarias se refiere lo cierto es que Chladenius señaló en el "Prólogo" a su Introducción a la interpretación correcta de discursos y escritos racionales de 1742 que estas necesitaban de una particular forma de interpretación (Szondi, 2006, pp. 64-65). Su especificidad nacía de que había que considerarlas de acuerdo con su naturaleza y condición, aunque asimismo asegura que es posible establecer conceptos que faciliten la comprensión perfecta de un pasaje (Szondi, 2006, pp. 67-69). Significa esto que la interpretación literaria dieciochista trató de encontrar un equilibrio mediante el cual el análisis, juicio o entendimiento de una obra literaria no fuera una mera cuestión de instinto, de gusto, de distancia cronológica o de disposición anímica. Al contrario, la comprensión tenía que fundamentarse, debía conseguir alcanzar el “concepto" como proponía Chladenius, y para ello era preciso encontrar un marco conceptual, unos referentes estéticos, un conocimiento del contenido y un procedimiento de trabajo que no solo validaran los resultados de la interpretación, sino que además sirvieran para educar y orientar en el modo en el que los potenciales lectores, con independencia de su estado, responsabilidad y condición, debían acometer la comprensión de las obras ${ }^{8}$.

Este planteamiento se afianzó en el siglo XVIII pues fueron muchos los eruditos y críticos que afrontaron profesionalmente el hecho en sí de entender las obras poéticas. Según hemos podido comprobar, en la segunda mitad de aquella centuria existió una necesidad de configurar los principios y métodos conforme a los cuales debería organizarse una hermenéutica literaria aplicable a todos los escritos de esta naturaleza. Es evidente que en la Ilustración se desarrolla un espíritu filológico y crítico dirigido a explicar, entender y juzgar los escritos en general y las obras literarias (ficcionales) en particular. Al siglo XVIII y a la Ilustración le interesa, y mucho, estudiar los fenómenos históricos, pasados y presentes, dotarles de sentido y hacerlo a partir de unos principios objetivos $u$ objetivables con los que fuera posible entender y juzgar de forma acertada y veraz el sentido de los textos, no pretendiendo reconstruir una hipotética intentio auctoris ${ }^{9}$. En este sentido, enfrentarse

\footnotetext{
${ }^{7}$ Szondi plantea en su conocida Introducción a la hermenéutica la cuestión misma de la existencia de esta disciplina. Parte del supuesto de que, si bien es dudoso poder fijar el sentido exacto de lo que los textos significaron en una época concreta e igualmente creer que hoy en día es posible una hermenéutica literaria material (que incluya la práctica) de la interpretación de los textos, lo cierto es que la hermenéutica literaria ha de ser una teoría que relacione filología y estética, aunque esté históricamente condicionada y no pueda proponerse como universalmente válida (2006, pp. 57-58 y 233-238).

${ }^{8}$ Chladenius reconoce esa individualidad del hecho de comprender. Así, distingue entre una comprensión directa, que relaciona con la certeza del objeto y que permite su universalidad interpretativa, y una comprensión indirecta, no universal, que depende "del uso de las disposiciones de nuestro ánimo, en virtud de las cuales suscitamos en nosotros mismos, a partir del entendimiento directo, toda clase de otros conceptos e impulsos" (Chladenius, 1742, \&529). La cita y la explicación procede de Ferraris, 2000, p. 82.

${ }^{9}$ Según afirma Chladenius, lo que un texto expresa puede generar pensamientos que pueden coincidir o no con los que el autor espera provocar con su discurso. Los lenguajes simbólicos, y más la literatura, donde la imaginación del creador actúa como elemento fundamental para causar deleite en los lectores, permiten crear las circunstancias en la que se supone acontece una historia de la que sus lectores no tienen ni han de tener un conocimiento real preciso. Así señala: “The intention of an author in a passage or book, or in general in any presentation whatsoever, is the limitation of the idea he
} 
a la literatura conllevó, al decir de quienes reflexionaron sobre ello y no tanto, como es lógico, del lector común, un conocimiento y este solo podía regirse por principios de índole general representativos, a su vez, de una metodología de mediación objetiva de base retórico-linguística (Rodríguez Sánchez de León, 2019a). Pero, como se ha señalado, el hecho en sí de interpretar (como también el de crear o el de conocer en cualquier campo del saber) activa facultades no propiamente intelectivas sino también emocionales o sensibles.

La segunda precisión hace referencia precisamente a ello. En el ámbito de la comprensión general así como en el particular dominio de la interpretación literaria se incorporarán reflexiones que transcienden la creación de un método objetivo, lógico o "filosófico" para comprender la literatura. Junto a la explicación o entendimiento mediato de la literatura, es decir, aquel que surge de la creación de una mediación objetivable, más o menos neutra, de aproximación a la literatura por la aceptación de unos criterios generales, lingüístico-retóricos y poéticos, se irán introduciendo en el terreno de la interpretación literaria explicaciones, comentarios o propuestas que suponen la aceptación del papel que lo psicológico habrá de desempeñar en ese proceso comprensivo. Hay que advertir, sin embargo, que la propia filosofía de la Ilustración (y aun la anterior) recogió a través de no pocos autores y de importantes tratados la idea de que el problema del conocimiento recaía en percepciones e interpretaciones tan intuitivas o emocionales como racionales.

En función de ello, transitaremos por ese campo de la hermenéutica literaria y de su configuración a partir de la confluencia entre el nivel de comprensión intelectual, originado en el racionalismo filosófico y sus diversas modalidades, y la consideración psicológica implícita en la percepción estética, emocional y hasta vivencial de la literatura. De hecho, el gran problema al que habrá de enfrentarse la hermenéutica es el que reconoce el propio Chladenius. Si una obra literaria causa placer a la imaginación, ¿la he comprendido en su totalidad? ¿Han cumplido el texto y el autor con su finalidad o, por el contrario, debe el lector aprender a trascenderlo alcanzando un nivel superior de entendimiento? Lo expresa del siguiente modo:

Las historias [de ficción] también son contadas y escritas a fin de divertir al lector y al oyente. Debe de haber algo en ellas que cause placer cuando las imaginamos. Si en la lectura o audición de una historia de este tipo, focalizo mi atención solo en lo que es capaz de procurarme placer y si consecuentemente la experiencia de placer es lo que se pretende, entonces he comprendido completamente el libro. Esta categoría abarca las muchas colecciones de historias entretenidas que uno no puede entender en su totalidad si no se da cuenta del placer que causan (Mueller-Vollmer, 2000, p. 55, \&151).

\section{Explicación filosófica de la lectura}

Parece una obviedad afirmar que la asignación de la condición de la belleza es el resultado de una experiencia humana de carácter estético. Sin embargo, percibir lo artísticamente bello,

had of the thing or in regard to the pass. [...] His aim throughout the entire story is to delight readers, for he knew that this meaningful way of composing was bound to please most readers" [La intención de un autor en un pasaje o en un libro o, general, en cualquier exposición, está limitada por la idea que él tiene del asunto o respecto del pasaje. [...] Su propósito a lo largo de todo el relato es deleitar a los lectores ya que conoce que de su significativa forma de componerlo dependía el agradar a la mayoría de los lectores] (1742: §694 y 695). 
comprenderlo como tal, comporta dos posibilidades que sitúan en polos extremos: considerarlo como el resultado de un aprendizaje intelectual equivalente al conocimiento teórico propio de cualquier orden de cosas, o bien ser el resultado de una percepción personal, subjetiva, individual por la cual los objetos y las obras nos resultan o no bellos o, lo que viene a ser lo mismo, placenteros. Digamos, pues, que la actitud hermenéutica podrá oscilar entre dos extremos que suponen una posición lógicofilosófica y una actitud fuertemente psicologizada del acto de comprender.

Entender que la interpretación supone un acto consciente en el que el lector o intérprete se enfrenta a las obras para hallar su sentido supone que puede hacerlo de forma intelectualmente consciente. Significa esto que adopta una actitud distante según la cual la interpretación de los textos equivale a ofrecer una explicación. Explicar, entonces, implica que la obra habrá de analizarse respecto de "algo", es decir, conforme a principios o criterios que se materializan en el discurso de los que habrá de disponer el intérprete. Cada texto representa una elección de su autor y una forma particular de expresar los fundamentos propios de su condición genérica y estético-literaria. Así, si de una tragedia se trata, la categoría de los personajes, los sucesos o el final desgraciado habrán de estar presentes en la forma del discurso. El lector entonces referencia su interpretación a un conocimiento previo sobre el que la proyecta. La cuestión es que ese conocimiento no puede ser meramente experiencial o, en caso de serlo, implica una abstracción que finalmente configura en la mente una idea de lo que es, debe de ser o parece ser la obra de arte. Pero dejarlo al libre criterio de los lectores significa confiar en que la reiteración de hábitos lectoriales organice por abstracción y sin errores las ideas de lo exigible a las obras literarias. Sin embargo, aceptar que cada lector referencie su interpretación a su particular concepto del discurso supondría, para un hombre del Setecientos, admitir que la lectura no precisa de un saber técnico y/o teórico. Tal posibilidad no se contempla o, más bien, no se plantea como ideal lectorial.

Por el contrario, quien se enfrenta a la literatura con ánimo de "comprenderla" ha de disponer de referentes teóricos y prácticos con los que podrá emprender esa tarea. Dos cuestiones subyacen aquí: la primera es que la interpretación/lectura no es un acto banal sino que depende de que el intérprete disponga de una serie de conocimientos previos susceptibles, a su vez, de ser expuestos de forma lógica y sistemática e incluso de mostrarse como demostrables o verdaderos. La segunda, consecuencia de la anterior, es que la interpretación es un arte que exige de una profesionalización. Es el trabajo que ejecuta el sabio, el erudito en el mejor sentido del término (Álvarez Barrientos, 2019, pp. 15-39 y Rodríguez Sánchez de León, 2019a, pp. 125-149). Así entendido, la teoría poetológica no es solo el resultado de la adopción del clasicismo perpetuado por la tradición occidental como fundamento del arte poético, sino que supone una manera universal y hasta ontológica de objetivar el ser de lo literario al que el lector ha de referenciar su comprensión del texto.

Según lo apuntado, la reflexión teórico-crítica del siglo XVIII procuró ofrecer recursos y formación para que se pudiera institucionalizar y socializar una interpretación intelectualmente objetiva o, más exactamente, objetivada de lo literario. Esta consiste en propiciar el conocimiento de las leyes del arte y de un saber histórico-crítico mediante los cuales es posible distanciarse de una mera 
percepción emocional de la literatura no sujeta a criterios de racionalidad argumentativa. La lectura es entonces una "operación del entendimiento" y, como tal, se basa en idénticos fundamentos lógicos. Para encontrar el sentido, lo mismo que para construir juicios, es necesario disponer de conceptos previos, procedentes del conocimiento de las lenguas y de las épocas, pero que se sustentan en deducciones e incluso en juicios previos que consiguen que se puedan explicar incluso las sensaciones o emociones que una obra literaria pueda causar. Du Marsais definía en su Lógica el raciocinio diciendo:

El raciocinio consiste en deducir, en inferir, en sacar un juicio de otros juicios ya conocidos o, por mejor decir, en manifestar que el juicio de que se trata se ha formado ya de un modo implícito de manera que ya no se intenta sino el desentrañarlo y hacer ver la identidad que tiene con otro juicio anterior (Du Marsais, 1785, p. 92).

Según esto, la inducción es un procedimiento de acceso a la verdad yendo de lo particular a lo general. El mismo autor lo confirma al decir: "La inducción es también una especie de raciocinio por el cual se procede del conocimiento de muchas cosas particulares al conocimiento de una verdad general" (1785, p. 193). De forma conclusiva explica que las operaciones del entendimiento son tres:

La primera [consiste] en acordarse de la idea ejemplar de aquello que se quiere juzgar. [...] La segunda en examinar si el objeto de que se trata es o no conforme a esa idea ejemplar. La tercera en expresar en la consecuencia lo que se piensa acerca de esta conformidad u oposición (1785, pp. 194-195).

Como resultado, establecer un método consiste en "el arte de disponer las ideas y los raciocinios de modo que uno mismo pueda entenderlas con más orden y hacérselas entender con mayor facilidad a los demás" (Du Marsais, 1785, pp. 195-196). Y acaba por señalar que habiendo dos especies de método para enseñar, uno analítico y otro sintético, el primero resulta "el más propio porque sigue la historia de las ideas conduciéndonos de lo particular a lo general” (1785, p. 197).

Aplicado este planteamiento a los estudios literarios, el salto entre interpretar y comprender supondrá que los hombres de letras del siglo XVIII tendrán que ofrecer a los lectores instrumentos interpretativos de carácter universal con los que sea posible valorar el pasado y el presente de la literatura de forma exacta y veraz. Con ello lo que se pretende es atenuar las distancias lingüística, estética e histórica hasta casi hacerlas desaparecer. Esto se consigue al fundamentar la lectura y la interpretación en la legitimidad universal de los principios poéticos y en el conocimiento de un saber filológico técnico que, expuesto de forma racional, se reafirmará por igual en los intérpretes cualificados que en los lectores comunes. La lectura se examina así en términos cuasi denotativos, basada en la existencia de lectores capaces de averiguar lo que las palabras dicen o significan de manera netamente referencial, y de un conocimiento poético-histórico, en términos de constatación técnico-empírica de los principios del arte y su presencia en la tradición. Con palabras de Gadamer, la reflexión teórica setecentista tendrá que asumir una función hermenéutica que se traducirá en hacer de esta "el arte de explicar por nuestro propio esfuerzo de interpretación lo que ha sido dicho por otros y lo que hallamos en la tradición" (2013, p. 152). Así, el sentido de una composición literaria se concede yendo más allá de lo que las palabras significan pues el explicar comporta observar la 
conformidad de las obras con unos patrones artísticos sancionados por la historia de la poética y de la literatura por resultar imprescindibles para entender artísticamente esta clase de textos. Digamos, pues, que es imprescindible transcender lo lingüístico-verbal, la lectura mediata para comprender el sentido de la obra artística y de la emoción que provoca. Se trata, como ya planteara el humanismo renacentista italiano, de fundamentar sobre la naturaleza formal del discurso artístico y sus contenidos (como propusiera Chladenius) las bases en términos absolutos de una hermenéutica literaria objetiva. Interpretar, más allá de entender el texto en su lenguaje, equivale a dotar de sentido artístico las producciones literarias. Y hacerlo consiste en reconocer los efectos que causa el cumplimiento o no de las normas que los hombres cultos y la tradición han prescrito y siguen prescribiendo por su carácter de ineludibles a nivel composicional. Estas se erigen entonces en las reglas conforme a las cuales puede verificarse una interpretación general de modo que su establecimiento o aceptación ha de preceder o, como mínimo, han de estar presentes en las interpretaciones concretas de lo literario en el Siglo de las Luces ${ }^{10}$.

\section{Lo psicológico y el hallazgo del "sentido estético" de la literatura}

En el lado de lo psicológico se sitúan autores como Jean-Baptiste Du Bos en sus Reflexiones críticas sobre la poesía y la pintura (1719), Addison y su Ensayo sobre los placeres de la imaginación publicado en The Spectator (1712) o Shaftesbury en varios de sus escritos, por mencionar algunos autores conocidos. Citando solo al primero, nos encontramos que justifica la diversidad de gustos en el caso de la poesía y cómo sus principios quedan supeditados a la propia finalidad de esta la cual, según el autor, consiste en agradar o resultar placentera (2007, 321-322 y Charlton 1989: 151$162)^{11}$. Desde esta perspectiva, lo que se plantean es si en el ámbito de la interpretación, de la crítica literaria o de la recepción existe ese espacio para que la experiencia estética se referencie a la emoción o a lo vivencial (imaginaria o real) del sujeto receptor sin la mediación apriorística de determinismos racionales. Como sin ninguna clase de duda plantea en época romántica Schleiermacher, el estatus de lo psicológico resulta tan imprescindible como el lingüístico-gramatical. Cree necesario que el intérprete esté dotado de ambas competencias, la gramatical y la psicológica, pues sin ellas no considera posible que la interpretación se realice con éxito:

El éxito del arte de la interpretación depende, por una parte, de la competencia lingüística y por otra de la capacidad de conocer a las personas. Por "competencia lingüística" me refiero a la facilidad para aprender lenguas extranjeras [...]. La habilidad de conocer a las personas se refiere especialmente al

\footnotetext{
${ }^{10}$ Este planteamiento se encuentra recogido en Ensayo de un arte general de la interpretación (1757) de Georg Friedrich Meier. Véase Szondi, 2006, pp. 133-151.

${ }^{11} \mathrm{Du}$ Bos explica que en el caso de los poemas el lector debe apreciar las bellezas del estilo y reflexionar acerca de los méritos o faltas que respecto de las reglas contiene. Sin embargo, reconoce que el lector a menudo se abandona ante las sensaciones placenteras que una obra le causa e incluso asegura que, aunque se le desengañe, el placer no disminuye. Por eso, señala que antes se prefieren los poemas que emocionan a los que destacan por su regularidad (2007: 134-135). El término estilo ha de entenderse en un sentido muy similar al que recoge Luzán en su Poética: “[...] llamóse estilo la locución y la manera particular de explicar sus pensamientos que tenía cada uno" (2008, 353). Sobre Addison, puede verse mi trabajo Rodríguez Sánchez de León (2019b).
} 
conocimiento del aspecto subjetivo determinante en la composición de pensamientos (Mueller-Vollmer, 2000, p. 76). ${ }^{12}$

Esta distinción nos lleva a reflexionar acerca de si en el siglo XVIII puede admitirse, sobre todo públicamente, que las competencias lingüística y retórica e incluso la poética son suficientes para interpretar la literatura. La finalidad placentera o el alcanzar el "sentido estético" que el arte procura se entiende que son intrínsecos a su naturaleza. Pero, por lo mismo, se concluye que el placer generado por las artes de la imaginación no puede limitarse a la comprensión retórico-poética del discurso. En otras palabras, ¿es la ilusión estética el fundamento de la interpretación literaria?

Si por "ilusión estética" entendemos, como plantea Werner Wolf, "la sensación placentera, de intensidad variable, que puede ser provocada por muchas, aunque no todas, obras de arte, de sentirnos imaginativa y emocionalmente inmersos en un mundo representado o en parte de él, y de experimentar ese mundo, ya sea que su referencia sea real o ficticia, de forma similar, aunque no idéntica, a la vida real, sin dejar de ser conscientes de que esta experiencia es imaginaria y ha sido suscitada por una obra y no por la realidad" (2013, p. 184), es evidente que esta se manifiesta durante el acto de lectura o de recepción literaria. La "ilusión estética” forma parte del hecho en sí de leer y de interpretar la literatura de la que el receptor no solo asume su condición de ficcional, sino que acude a ella precisamente para experimentar las emociones de diversa índole que puede suscitarle.

Atendiendo a ello, resulta que la composición de la obra literaria y su interpretación de forma más racional que emocional conlleva que se causa en el sujeto un distanciamiento, incluso un rechazo estético (no necesariamente por novedoso sino por reconocible y no placentero), que lo aleja de la función catártica, en el sentido que le asigna Jauss, buscada o esperada por el lector (1992: 159). En cambio, cuando la relación con lo artístico no está mediada por la teoría del arte ni por la ideología dominante, el lector puede libremente alcanzar la autocomplacencia o el placer sentimental. Este efecto de la experiencia estética y de la libertad individual implica "un placer que en las propias emociones producen la oratoria y la poesía y que pueden llevar al oyente o al espectador a cambiar de criterio o a liberar su ánimo" (Jauss 1992: 159). Tan alto poder comunicador no se concibe en tiempos de la Ilustración. Mas sí se expresó que en la interpretación emocional pueda darse alguna clase de identificación natural y espontánea. Volviendo a Du Bos este afirma:

La filosofía, que enseña a juzgar las cosas por los principios que le son propios, enseña al mismo tiempo que, para conocer el mérito y la excelencia de un poema, hay que examinar si gusta y hasta qué punto gusta y afecta a quienes lo leen (2007, p. 325).

No obstante, el cambio de criterio mencionado por Jauss puede derivar en una racionalización o análisis del sentimiento. Entendámoslo mejor como un cambio de gusto. Digamos que el sujeto puede reconocer de forma consciente las habilidades del autor que han provocado esa emoción primera. Pero en cuanto a la liberación del ánimo, la relación del lector con el objeto artístico, y aun con el sujeto

\footnotetext{
${ }^{12}$ En realidad lo que se plantea en la línea de pensamiento que deriva de Locke y de Condillac es que el lenguaje mismo es imperfecto en la traslación del pensamiento. Entre el lenguaje y el pensamiento hay un espacio vacío que debe completar, deducir o interpretar quien escucha o lee (Schleiermacher, 1998, p. 10). Y esa situación se acentúa en el caso de las obras literarias o del lenguaje literario.
} 
que lo produce, puede elevarse al nivel de alcanzar una identidad emocional liberadora no consciente, la conmoción, pues las imágenes se procesan de forma natural, espontánea o automática siguiendo bien disposiciones innatas, bien disposiciones adquiridas pero de carácter experiencial, emocional y no necesariamente intelectualizadas. Responde este proceso a una emoción primaria en la terminología de Antonio Damasio.

En esa misma línea de pensamiento se inserta el pensamiento de Addison cuyo Ensayo sobre los placeres de la imaginación (1712) recoge la idea de que las ficciones, placeres secundarios, son efectivas en la medida en que procuran una imagen que conduce al oyente o lector hacia la recreación imaginaria. Tal recreación se adentra en los dominios de lo íntimo y pertenece tanto al ámbito de la intelección como al ámbito de la emoción estética. Más aún, esta última puede ser el origen del placer sin que se acompañe de un razonamiento. De hecho, ese será el gran problema del clasicismo e incluso del pensamiento ilustrado, a saber, de qué manera convencer de las bellezas y bondades del arte frente a quienes sienten o admiran contraviniendo el dictamen de los eruditos y sabios ${ }^{13}$.

Según replica Antonio Damasio a Descartes en Las pasiones del alma, "el error de Descartes”, como titula su libro, se halla en asegurar que las inclinaciones naturales son controladas por la razón y la voluntad, doblegándose a ellas. Muy al contrario, Damasio explica biológicamente cómo los mecanismos conductuales por los que se rigen las pulsiones e instintos resultan de una actividad combinada entre lo arcaico y lo racional, las estructuras cerebrales inferiores y las superiores. Simplificando sus ideas, significa que en las primeras se encuentra el mundo de las emociones y en las segundas la racionalidad y el conocimiento. Pues bien, su propuesta consiste en afirmar que lo racional se construye a partir de lo biológicamente más básico de forma que la facultad de razonar es una actividad combinada (1999: 152). Esta posibilidad, que el Setecientos quiso formular filosóficamente para doblegar lo que podemos denominar "el gusto de la audiencia", pretendía neutralizar la impulsividad del gusto, según ha recogido la llamada "teoría cognitivista"14. Para esta las emociones tienen un sustrato cognitivo y no meramente sensitivo como ya sostuviera Aristóteles en su Retórica (Camps 2012: 26) ${ }^{15}$. Pero más allá de esta pretensión, se hallaba la constatación receptiva mediante impulsos no intelectualizados y no fácilmente intelectualizables (Núñez Ramos, 2017) ${ }^{16}$.

\footnotetext{
${ }^{13}$ En la línea del pensamiento kantiano lo que se dirime, por una parte, es la distinción entre el uso público y el uso privado de la razón y, por otra, el cuestionamiento, del que no falta una dimensión ético-moral y otra religiosa, sobre si resulta o no suficiente la moral natural.

${ }^{14}$ Francisco Mariano Nifo si bien lo expresaba en 1764 diciendo: "Si nosotros fuéramos ángeles o puras inteligencias, esto solo nos bastaría en las obras del ingenio, pero como somos más sensibles que racionales, la verdad siempre sola nos enojaría. Ella no puede aficionarnos a su hermosura sino cuando habla a nuestra imaginación y a nuestro corazón (1764: 28), no duda tampoco en reivindicar, junto con la necesidad de interesar, el "bello de gusto, establecido sobre el conocimiento de las obras de la naturaleza y sobre las producciones de los grandes maestros que dirige el empleo del bello esencial" (1764: 21).

${ }^{15} \mathrm{Si}$ para el siglo XVIII hablar de emociones presentaba problemas de racionalidad cognoscitiva, mencionar las pasiones constituía un complejo problema teórico y poético. Sobre la relación entre las emociones y la persuasión racional, véanse los trabajos de Cooper, 1996, pp. 238-257 y Nussbaum, 1996, pp. 303-323 y sobre la distinción entre emoción y pasión, su definición y su representación en la literatura Rodríguez Sánchez de León, 2013, pp. 103-114.

${ }^{16}$ Alexander Gerard en su conocido Ensayo sobre el gusto (1759) explica esa independencia de la voluntad diciendo "it is a power which recieves its perception inmediately, as soon as its object is exhibited, previous to any reasoning concerning
} 
La filosofía y la psicología en la hermenéutica literaria de la Ilustración

No faltan ocasiones en las que ese espacio lo ocupa el interés del lector por la obra escuchada o leída, junto con lo que el periodista Francisco Mariano Nifo denomina "el orden natural". En su apología La nación española defendida de los insultos del Pensador y sus secuaces (1764), lo define diciendo:

El orden natural tiene su poder en los primeros sentimientos de la naturaleza, como se manifestó antiguamente en Roma, cuando se oyó decir la primera vez en el teatro aquel bello verso de Terencio: "Homo sum, humani nihil a me alienum puto" (1764, p. 22).

Solo a través del sentimiento o, si se prefiere, del sentimiento de lo bello natural, espontáneo o instintivo y emocional podrá verificarse una comprensión auténtica de lo artístico-literario como representación o simbolización de la belleza, sin la cual será a su vez imposible que se realice un entendimiento analítico, profundo y social de la literatura. La poesía en sentido general no es sino la expresión también de las sensaciones del poeta que, provisto de imaginación y otras dotes artísticas, las formaliza en un discurso, en una composición artística que se adecua a sus necesidades emocionales, expresivas e históricas. Así, utilizará un lenguaje simbólico para suscitar en el lector una emoción más elevada que la que el sentimiento por sí solo alcanzaría. A la emoción que deriva del sentimiento de identificación o empatía entre dos subjetividades, se añade la excepcionalidad expresiva y discursiva que alejan al poeta, hasta encumbrarlo, del hombre común.

Esta inversión de lo comentado con anterioridad le permite, según explica Meléndez Valdés, instrumentalizar el arte para perfeccionar su discurso no solo por motivos retórico-poéticos sino porque se sirve de sus recursos para emocionar. Dicho de otro modo, la emoción estética posee una condición única pues, sobre la base de lo lingüístico-formal o la belleza del estilo, se construye una ficción capaz de suscitar de forma indisociada la emoción ante el arte y por el arte. La materialidad del discurso es un instrumento evocador que facilita el encuentro del lector con el poema y, por extensión, con su autor, elevándonos sobre nosotros mismos mediante un esfuerzo aprehensivo generador de emociones y sensaciones propias. El propio Meléndez reconoce que la composición de algunos de sus primeros poemas dejó impresiones muy profundas en su corazón. Incluso defiende que el poeta, lírico en este caso, no explique sus versos. Refiriéndose a sus poemas filosóficos, comenta:

[...] El que los lea suplirá fácilmente cuanto [...] le comentara o explicara yo, además del gusto que se siente en representarse cualquiera por sí mismo toda la cadena de ideas que abrazaba el autor cuando escribía. No todo se ha de decir y el quererlo decir todo es el medio más seguro de fastidiar (XVIII-XIX).

the qualities of the objet or the causes of the perception. It is a power which exerts itself independent of volition, so that, while we remain in proper circumstances, we cannot, by any act of the will, prevent our receiving certain sensations, nor alter them at pleasure, nor can we, by any means, procure these sensations, as long as we are not in the proper situation for receiving them by their peculiar organ" ["Es un poder que recibe su percepción de forma inmediata, tan pronto como el objeto es presentado, previo a cualquier razonamiento relativo a las cualidades del objeto o las causas de su percepción. Es un poder que se ejerce con independencia de la voluntad, de modo que mientras permaneces en las mismas circunstancias, no podemos, por ningún acto de la voluntad, impedir que se reciban ciertas sensaciones, ni alterarlas en su placer, ni podemos, por cualquier medio, procurar esas sensaciones como si estuviéramos en la situación para recibirlas por sus propios medios"] (1780, p. 146). 
En virtud de lo expuesto, el placer artístico no ha de ser siempre un sentimiento racional como criticaron Diderot o Addison. El hecho de no serlo para muchos lectores no merma su mérito ni su funcionalidad artística. Al contrario, sitúa a la literatura en una posición privilegiada respecto del hombre y de la humanidad. "La imitación produce dolor y placer, no porque se confunda con la realidad, sino porque nos las recuerda", dice Samuel Johnson al comentar el teatro de Shakespeare (2003, p. 38 y Gomá, 2015, pp. 266-275). La Modernidad, como escribe Javier Gomá, consigue plantear que el hombre es en sí mismo un cosmos que ha resolver o, por lo menos, cuestionarse la incidencia del ser del sujeto en los procesos de conocimiento o de percepción estética (2015, pp. 266267). A ello convendría añadir el problema asociado, y no menor, de lo que para la época puede suponer la consciencia de la ficción.

A tenor de lo dicho, no es preciso que se realice una "socialización" de la lectura. Siendo un acto de socialización la escritura, la lectura puede implicar un acto no mediado en el que el lector se abandona para sentir y emocionarse al advertir el sentido de una obra, el que adquiere para sí mismo o el que, desde el punto de vista ficcional, le sugiere. La identificación con lo escrito y, si acaso, con el poeta se realiza mediante ese proceso de actualización e inmersión que implica en sí el acto de leer. Y este acto puede referenciarse al propio mundo vital tras el que se halla la capacidad ineludible de la literatura para emocionar: "No es extraño - dice Addison - que nos deleiten las pasiones capaces de producir la esperanza, la alegría, la admiración, el amor y otras semejantes porque jamás se excitan estas sin que vayan acompañadas de un placer interno" (1991, p. 189). La relación entre las emociones y el arte es estrecha e innegable como fuente de placer espiritual, como efecto emocional. Pero a él se añade otro no menos poderoso, el de suscitar imágenes. Aunque no lo escribe exactamente con esta intención, la frase de Addison resulta oportuna: “[...] No nos deleita tanto la imagen contenida en la descripción, como la aptitud de la descripción para excitar la imagen” (1991, p. 188). Digamos que es cualidad admirable en el poeta la que le permite crear imágenes tan poderosas como para generar otras propias y únicas en el lector referenciadas a sí mismo y a su capacidad de imaginar. Luego el lector puede experimentar el placer de emocionarse con una ficción tanto porque lo representado le llega a los sentimientos albergados en lo más profundo de su alma, como porque alienta su imaginación y su recuerdo configurando en su pensamiento imágenes alternativas (1991, p. 132). Digamos entonces que el placer artístico sí puede gozar de cierta autonomía, sin la cual el arte y la literatura estarían condenados a desaparecer. Otra cosa es que la sensibilidad pueda formarse como quiso el siglo XVIII.

En cualquier caso, la cuestión es que la hermenéutica setecentista y, en particular, la hermenéutica literaria no pudo prescindir del determinismo de lo psicológico, probablemente también porque este había invadido el campo de la filosofía. Aun así, quedaba claro que no solo la recepción sino la interpretación necesitaba de ese componente psicológico, sensible o emocional (que abarca desde la intuición a la emoción) por su poder sugeridor y su capacidad para elevar al sujeto que lee o comprende hacia un estado mental en el que intervienen capacidades no lógicas (imaginación, fantasía, 
sensibilidad) gracias a las cuales se percibe el arte como objeto estético y no solo como producto intelectual.

\section{Bibliografía}

Addison, J. (1991). Los placeres de la imaginación y otros ensayos de The Spectator. Madrid: Visor. Álvarez Barrientos, J. (2019). La profesión de las letras: el erudito Juan Andrés. En Rodríguez Sánchez de León, M. a J. y Amores, M. La ciencia literaria en tiempos de Juan Andrés (17401817). Madrid: Visor, 15-40.

Camps, V. (2012). El gobierno de las emociones. Barcelona: Herder.

Charlton, D. G. (1989). Jean-Baptiste Du Bos and Eigtheenth-Century Sensibility. Studies on Voltaire and Eighteenth Century, 266, 151-162.

Cooper, J. M. (1996). An aristotelian theory of the emotions. En Oksenberg Rorty, A. (ed.), Aristotle's Rhetoric. Berkeley: University of California Press, 238-257.

Couzens, D. (1982). The critical circle. Literatura, History, and Philosophical Hermeneutics. Berkeley: University of California Press.

Damasio, A. (1999). El error de Descartes. La razón de las emociones. Barcelona: Andrés Bello.

Du Bos, J.-B. (2007). Reflexiones críticas sobre la poesía y la pintura. Valéncia: Universitàt de Valéncia.

Du Marsais, Mr. (1785 [1769]). Reflexiones sobre las principales operaciones del entendimiento. Madrid: Miguel Escribano.

Ferraris, M. (2000). Historia de la hermenéutica. Madrid: Akal.

Gadamer, H.-G. (2013). Hermenéutica, estética e historia. Salamanca: Sígueme.

Gerard, A. (1780 [1749]). An essay on Taste. Edinburgh: J. Bell and W. Creech.

Gomá, J. (2015). Imitación y experiencia. Madrid: Taurus.

Grene, M. (1943). Gerad's Essay on Taste. Modern Philology, 41/1, 45-58.

Jauss. H. R. (1992). Experiencia estética y hermenéutica literaria. Ensayos en el campo de la experiencia estética. Madrid: Taurus.

Johnson, S. (2003). Prefacio a Shakespeare. Barcelona: Acantilado.

Luzán, I. de. La Poética (2008). Ed. R. P. Sebold. Madrid: Cátedra.

Meléndez Valdés, J. (1797). Poesías. Valladolid: Viuda e hijos de Santander. T. I.

Mueller-Vollmer, K. ed. (2000). The Hermeneutics Reader. New York: Continuum.

Murcia Conesa, A. de. (2019). Georg Friedrich Meier y el Ensayo de un arte general de la interpretación. Una hermenéutica para un mundo perfecto. En Rodríguez Sánchez de León, M. ${ }^{a}$ J. y Amores, M. La ciencia literaria en tiempos de Juan Andrés (1740-1817). Madrid: Visor, 151-174.

Nifo, F. M. (1764). La nación española defendida de los insultos del Pensador y sus secuaces. Madrid: Gabriel Ramírez. 
Núñez Ramos, R. (2017). La lectura como experiencia. Entre Aristóteles y la neuroestética. Tropelías, $1,221-235$.

Nussbaum, M. C. (1996). Aristotle on emotions and rational persuasion. En Oksenberg Rorty, A. (ed.). Aristotle's Rhetoric. Berkeley: University of California Press, 303-323.

Recio Ariza, M. ${ }^{a}$ A. (2019). La hermenéutica y la crítica según Ast: importancia y significación de su traducción al español. En Rodríguez Sánchez de León, M. a J. y Amores, M. La ciencia literaria en tiempos de Juan Andrés (1740-1817). Madrid: Visor, 175-184.

Rodríguez Sánchez de León, M. ${ }^{\mathrm{a}}$ J. (2013). “De la poética de la razón a la antipoética de la pasión: la actitud ilustrada” en Durán, F. (ed.). Hacia 1812 desde el siglo XVIII, Gijón: Trea, 103-114.

Rodríguez Sánchez de León, M. ${ }^{a}$ J. (2019a). El conocimiento científico y la comprensión hermenéutica y crítica de la literatura: la propuesta de Juan Andrés. En Rodríguez Sánchez de León, M.a J. y Amores, M. La ciencia literaria en tiempos de Juan Andrés (1740-1817). Madrid: Visor, 125150.

Rodríguez Sánchez de León, M. a J. (2019b). Varying life": the idea of fiction in the Spanish version of Joseph Addison's The pleasures of the Imagination. In. Ertler, K.-D. (ed.). Joseph Addison (16721719) and Europe. Frankfurt am Main, Peter Lang. En prensa.

Schleiermacher, Fr. D. E. (1998). Hermeneutics and Criticism. Cambridge: Cambridge University Press.

Szondi, P. (2006). Introducción a la hermenéutica literaria. Madrid: Abada.

Wolf, W., W. Bernhart y A. Mahler (2013). Immersion and Distance. Aesthetic Illusion in Literature and Other Media. Amsterdam: Rodopi. 